\title{
Remuneration and Recidivism: The Long-Term Impact of Unemployment Compensation on Ex-Offenders
}

\author{
David Rauma ${ }^{1}$ and Richard A. Berk ${ }^{2}$
}

\begin{abstract}
The relationship between unemployment and crime is the subject of research and debate. We present evidence that suggests that recidivism among ex-offenders can be reduced by providing unemployment compensation available immediately after their release from prison. A California program made such benefitstransitional aid-available during the late 1970s and early 1980s. Using a 5-year follow-up and a failure-time model, we show how recidivism among an eligible group was consistently lower over those 5 years than for an ineligible group.
\end{abstract}

KEY WORDS: recidivism; transitional aid; failure-time model; regressiondiscontinuity design.

\section{INTRODUCTION}

Recidivism is a problem as old as its precondition, imprisonment. Consider this statement, by the State Board of Directors of San Quentin prison in 1858, which states clearly some of the relevant issues:

Besides, after they leave the Prison, such is the uncharitableness of the world, that, with the mark of the Prison upon them, they find it almost impossible to obtain employment. They rarely find friends to extend an encouraging hand to them, and, meeting with no sympathy except amongst their old associates in crime, they come to the conclusion that society is waging an unrelenting warfare against them, and every honest impulse of their souls is destroyed. (Board of Prison Directors, California State Prison, 1858)

These sentiments are echoed in a later statement by the State Board of Prison Directors for California in their biennial report for 1902-1904:

Another serious question is, what shall become of the convicts after they are discharged? Under the present law they are given a small sum of money and a suit of clothes and transportation to the place from which they came; but unless they know a trade or had some means of earning a livelihood before they entered prison their sojourn within does not fit them for earning a livelihood after they leave its walls. (Board of Prison Directors, California State Prison, 1905)

'Department of Sociology, University of Michigan, Ann Arbor, Michigan 48109.

${ }^{2}$ Department of Sociology, University of California, Santa Barbara, California 93106. 
Prison officials are not alone in their selection of employment as a critical feature of the postprison experience. Over and over, parole agents, other criminal justice officials, and community leaders emphasize the importance of employment after release for the inmate's successful (i.e., noncriminal) readjustment to society. The exact link between employment and recidivism, and between employment and crime generally, is still the subject of research (Rossi et al., 1980; Freeman, 1983; Schmidt and Witte, 1984; Thornberry and Christenson, 1984) and debate (Zeisel, 1982; Rossi et al., 1982). But one well-known and seldom-disputed fact is that imprisonment does little to enhance the inmate's employment prospects after release.

Research on employment and crime has generally identified a nonpositive relationship between the two (i.e., employment does not seem to increase participation in crime), but any number of issues remain. Since most of the studies dealing with recidivism have concentrated on the first few months or the first year after release (e.g., Rossi et al., 1980; Maltz, 1984), the long-term relationship between crime and employment is uncertain. For example, it could be argued that, because of the employment patterns among ex-offenders, short-term studies miss the point. Many ex-offenders go from menial job to menial job, with sometimes substantial periods of unemployment in between (Glaser, 1964; Pownall, 1969; Witte, 1975, 1976). Therefore, short-term studies may capture only the effect of the first job after release and the pressures of parole agents and family to be employed. Once those pressures lessen, and/or the ex-offender experiences unemployment, there could be a return to criminality. In fact, Thornberry and Christenson (1984) found such a reciprocal relationship between crime and unemployment in a subsample of the Philadelphia birth cohort originally studied by Wolfgang et al. (1972).

We examine the issue of long-term effects for a group of ex-offenders released from California prisons during the later 1970s who, during their imprisonment, could have become eligible for unemployment compensation benefits after release. Based on information about eligibility for unemployment compensation and FBI "rap sheet" information, our finding is that, over the 5 years after release from prison, ex-offenders eligible for the benefits had a lower recidivism rate than the ineligible group. Our argument is that this finding is best understood in light of the intent of the program-to provide ex-offenders with monetary aid in their search for jobs-and in light of a theoretical link between crime and employment.

\section{BACKGROUND}

\subsection{The LIFE and TARP Studies}

Two of the most prominent studies of employment and crime were done in the early and mid-1970s and funded by the United States Department 
of Labor. The first of these, the LIFE (Living Insurance for Ex-Offenders) project, was conducted in Baltimore during the period 1971 to 1974. Its purpose was to test and compare the effects of weekly payments and job counseling on postprison adjustment. A total of 432 released offenders was randomly assigned to treatment and control groups: the treatment groups received some combination of job placement counseling and/or weekly payments of $\$ 60$ for 13 weeks; the control groups were "treated" as ordinary releasees from prison. [For a complete description of the program, see Lenihan (1978).]

The program was based on the seemingly simple notion that some crime is based on economic need. If certain crimes are financially motivated, some ex-offenders without a job and sufficient resources to support job search efforts might resort to illegal activities as a source of income. Lenihan $(1978$, p. 5) states that "implicit in such a perspective is the view that for some people, certain crimes of theft (robbery, burglary, and larceny) are economically rational acts-that is, for the person committing a property crime, the act is purposeful and, considering the alternative ways of getting money available to the offender, also efficient." Therefore, economic aid may provide enough income to prevent certain types of income-generating crimes. Alternatively, the aid may increase the costs to the perpetrator of all crimes: ex-offenders would have more to lose by committing crimes and perhaps being caught and might refrain from criminal activities entirely.

The results of the LIFE experiment were mixed but encouraging. There were no overall differences in recidivism rates between treatment and control groups (Lenihan, 1978, p. 3). However, the treatment group did experience a reduction in the number of arrests for property offenses relative to the control group. The payments appeared to work as intended, at least to the extent that further involvement in income-generating crimes was reduced.

The TARP (Transitional Aid Research Project) experiment came next, beginning where the LIFE experiment ended. A major goal of TARP was to replicate the LIFE results, while testing a wider array of treatments. One group of randomly assigned ex-offenders in the two states of Texas and Georgia received weekly payments of financial aid, for periods of 13 or 26 weeks, with tax rates on earnings of either 25 or $100 \%$ (earnings were taxed by reducing weekly payments accordingly). Ex-offenders in Georgia received $\$ 70$ per week, while those in Texas received $\$ 63$ per week. Another treatment group received job placement services and control-group members were again treated as ordinary releasees.

The monetary treatment in TARP was not a success overall. An analysis of variance showed no differences between the treatment and the control groups in either state for the number of arrests in a 1-year follow-up period (Rossi et al., 1980, pp. 91-95). But it had already been posited that a treatment effect might be masked by work disincentives due to the 
experimental payments. Released offenders receiving the payments could wait before finding work, or work less, and therefore have more time in which to commit crimes. Any reduction in criminality brought about by the payments might be canceled out by any increase in leisure time also brought about by the payments. Once these insights were incorporated within a "counterbalancing" theoretical model, and an analysis was conducted based on that model, the weekly payments were shown to have these effects: a reduction in work effort that led to an increase in arrests during the follow-up period, but also a reduction in the number of arrests for property and nonproperty offenses during that period once work effort was held constant. The TARP analysis is not without its critics [see Zeisel (1982) for a comment and Rossi et al. (1982) for a reply], and perhaps the most prudent comment on TARP is that, at worst, there were no treatment effects. At the same time, neither the experimental results nor the counterbalancing model showed the payments leading to an overall increase in criminal activity.

\subsection{California Senate Bill 224}

In response to the problems of recidivism and inspired by the LIFE findings, the California state legislature in 1977 passed Senate Bill 224 (SB224). The bill mandated that, beginning in July of 1978, adults released from prison could apply for unemployment insurance. Eligibility was to be obtained by working at prison jobs or by participating in prison vocational programs after January 1, 1977. For both kinds of activities, nominal earnings were accumulated at the then minimum wage of $\$ 2.50$ an hour (the real wage rate was closer to $20 \phi$ ). Prisoners who worked a minimum of $653 \mathrm{hr}$ over a 12-month base period were eligible for unemployment compensation benefits after release. The amount of benefits received depended upon the total number of hours worked in prison, with the effective range of support between $\$ 30$ and $\$ 70$ a week for up to 26 weeks.

The usual California state regulations applied to program recipients. These ex-offenders had to be looking seriously for work and were subject to the standard agency forgiveness provisions. An upper limit of $\$ 25$ a week could be earned with no reductions in payments, but for earnings in excess of $\$ 25$ a week, weekly payments were reduced dollar for dollar.

\subsection{An Economic Model}

As suggested by Lenihan's above-cited comment, an explicitly economic model was the foundation for the LIFE study; this was equally true for TARP and was incorporated in the design of SB224. The importance 
of an economic model for understanding the relationship between unemployment and recidivism specifically, and crime more generally, cannot be underestimated. As Thornberry and Christenson (1984, p. 398) note, the four major criminological perspectives-social control theory, strain theory, social learning theory, and integrated models_-"all adopt a unidirectional or asymmetrical causal structure... they ignore the possibility that crime and its presumed causes are embedded in a reciprocal causal structure, mutually influencing one another over the person's life span." Thornberry and Christenson $(1984$, p. 400) go on to state that "the hypothesis that unemployment influences crime is explicitly developed in most etiological theories of crime, while the reciprocal hypothesis, that crime also influences unemployment, is implicit in and can be derived from these same theories." While these authors do develop an empirical model specification based on these traditional criminological perspectives, we argue that, for an essentially economic problem, an economic model should also be consulted.

Since Becker's pioneering work in the 1960s (Becker, 1968), economists have formulated several different models of criminal choice. Although the various economic models are dependent on individual authors for their particular formulations, they do share a common orientation and, within categories of models, a common specification of the relevant variables. First, economic models are based on the notion that individuals make decisions partly on the basis of expected costs and benefits. Of particular importance is the concept of expected opportunity costs: the value of the next-best option given up when making one choice from among several options. For example, the decision to participate in crime, and therefore allocate a certain number of hours to illegal activities, means that less time would be available for legal activities. Legally obtained income would be reduced, or eliminated entirely if criminal activity resulted in time in jail or prison.

Second, there is the premise that individuals may allocate time (or in some models, income) to both legal and illegal income-generating activities and that their time allocation decisions will depend on the relative payoffs from each. Individuals may specialize in one activity or the other (e.g., honest citizens as opposed to career criminals), but splitting time between legal and illegal activities implies that the decision to commit a crime is not a simple either/or decision. It also implies that merely increasing an individual's legitimate income, perhaps through transfer payments, may not decrease his/her participation in illegitimate activities. Rather, the individual has the choice to decrease legal activities (i.e., substitute the transfer payments for legitimate work) or decrease participation in illegal activities (i.e., substitute for the illegitimate "work" instead).

Recently, Schmidt and Witte (1984) have formally presented several alternative models based on these economic assumptions. The most complex 
of these models (Schmidt and Witte, 1984, pp. 163-165) is consistent with the TARP counterbalancing model and with Thornberry and Christenson's reciprocal model of crime and unemployment. The Schmidt and Witte model postulates that time allocations to legal and illegal activities can occur in any order over time. This is in marked contrast to earlier economic models, where allocations to legal activities were assumed to take logical precedence. Rather, the time allocations can occur in either order and it is possible for allocations to change over time. Two important implications are that longitudinal studies are necessary for understanding the long-term relationship between crime and unemployment and that feedback between economic factors and criminal behavior must be taken into account.

As we detail in the next section, our data are limited to a longitudinal study of a particular type. We have data only on officially detected criminal activity during the 5 years after individual ex-offenders were released from California prisons. We have no unemployment information, and consequently we can estimate a model for criminal activity whose only economic factor is the initial exposure to the California program. In terms of the TARP counterbalancing model, we estimate a reduced-form equation for criminal activity. Nevertheless, we hypothesize that, based on an economic model and previous research (e.g., Lenihan, 1978; Rossi et al., 1980; Freeman, 1983), there will be reduction in recidivism as a result of SB224. For several reasons, we expect that the beneficial aspects of the treatment will not be cancelled by the work disincentives the payments create.

First, the relevant economic theory states that, in terms of opportunity costs, payments can have two effects. The payments themselves create opportunity costs-the money cannot be collected if the ex-offender is in jail or prison. And if the ex-offender finds a better job while collecting unemployment compensation, that job has opportunity costs-it is very likely lost if the ex-offender is reincarcerated. Second, law-abiding behavior such as employment may have its own utility. Put differently, there is a variety of social benefits accrued through law-abiding activity generally and employment specifically. For example, one can gain a larger friendship network and an increased social status (see Liker, 1982; Nock and Rossi, 1978). And of course there are the pressures that parole agents put on ex-offenders to become and remain employed. ${ }^{3}$ Finally, the weekly payments that ex-offenders in our sample received were, on the average, only $\$ 45$. This is in contrast to the $\$ 60$ and $\$ 70$ amounts that were part of the TARP treatment several years before. It is difficult to argue that $\$ 45$ is a strong

\footnotetext{
${ }^{3}$ Employed ex-offenders typically gain status with their parole agents. For example, drug addicts may be required to submit urine tests less frequently. But more generally, parole agents perceive a strong link between crime and unemployment and they treat employed ex-offenders as better risks than the unemployed.
} 
work disincentive for very many people. However, the weekly payments may have provided enough of a cushion such that, as in TARP, ex-offenders were more selective about employment and tried to find better jobs than they otherwise might have taken.

In summary, we expect to find that the unemployment compensation will lead to short-term decreases in criminality. Similarly, we expect such a finding to hold over time.

\section{DATA AND METHODS}

SB224 also mandated that an outcome assessment be done, and data collection for this evaluation was undertaken in two phases. Data were first obtained during 1980 and 1981 and are discussed by Rauma and Berk (1982). After a brief presentation of these data, we discuss additional data on the program obtained during 1984 and 1985.

The initial data set consisted of a sample of about 1100 releasees from California prisons who applied for the unemployment benefits and were followed for 10 months after their application for benefits. The vast majority of ex-offenders applied in the first month after release from prison, and approximately $80 \%$ of the sample was determined to be eligible for unemployment compensation. These data reflect an historical period when virtually all prisoners were released on parole, and therefore, recidivism during a 10-month period after release would necessarily involve a parole violation. Thus, a "failure," according to parole follow-up data maintained by the California Department of Corrections (CDC), was defined conceptually as any of the following:

(1) a felony offense resulting in parole revocation and/or return to prison;

(2) a parolee at large (PAL), resulting in parole revocation and/or return to prison;

(3) technical violations resulting in parole revocation and/or return to prison; and

(4) misdemeanors resulting in parole revocation and/or return to prison.

All other kinds of violations were not defined as failures because they were far less serious (e.g., vehicular offenses) or because their legal status was unclear (e.g., arrest and release). In brief, failure was defined in a manner that would reflect serious violations of parole and presumably a return to criminality. Thus, the outcome measure for the CDC data was 
basically a parole revocation that would, in principle, result in a return to prison. ${ }^{4}$

The CDC records used to define failure were limited in one important respect (beyond the usual kinds of problems one can expect to find in administrative files). Since parole periods did not last more than 2 years, the follow-up period was limited to at most 24 months. And due to the 2.5-year window from which the sample was drawn, no more than 10 months of follow-up data was available on the full sample at the time of the evaluation. Of course, given that the benefits lasted no more than 6 months and most ex-offenders applied early after release, a 10-month follow-up period should be sufficient to detect short-term effects. Surely, the total impact of several months of payments would be felt within a year. However, if one were interested in long-term effects, such as whether crimes were being postponed by the payments rather than eliminated, even the maximum follow-up period of 24 months is a serious constraint.

Additional data were collected on the original sample in order to address the question of long-term effect. FBI "rap sheets" were used as a source of information about criminal activity during the first 5 years after application for unemployment benefits. In contrast to the CDC data, the FBI data provided different types of information about criminal activities. Rap sheets seemingly give a wealth of information, but they lack explanations about such things as charge reductions from the time of arrest to adjudication and too often contain no information about the final disposition of arrests and court appearances. In order to use information consistently available, we coded events as failures when they met this criterion: arrests that resulted in a conviction for a nonvehicular offense and a minimum of 3 months in jail or prison. Conviction and time spent in jail were a screen for apprently minor cases, using the simple rule that, all things being equal, time actually spent in jail (and prison of course) was an indicator of a more serious crime.

If the FBI data had proved to be simply a complement to the CDC data, all would have been well. Unfortunately, efforts to compare FBI failures to CDC failures led to troubling anomalies. Figure 1 shows the cumulative number of failures during the follow-up period, in 6-month intervals, according to the source of the failure information. One readily apparent difference between the CDC and the FBI data is that, since the CDC data do not follow a parolee for more than 24 months, the CDC-only curve is flat after 24 months. More importantly, however, there are increasingly larger disparities between the CDC and the FBI data, even in the first

\footnotetext{
${ }^{4}$ Often, time spent in jail prior to a revocation is subtracted from one's sentence. Consequently, it was possible to have a parole revoked, have the original sentence reimposed, and still not serve time in a state prison.
} 


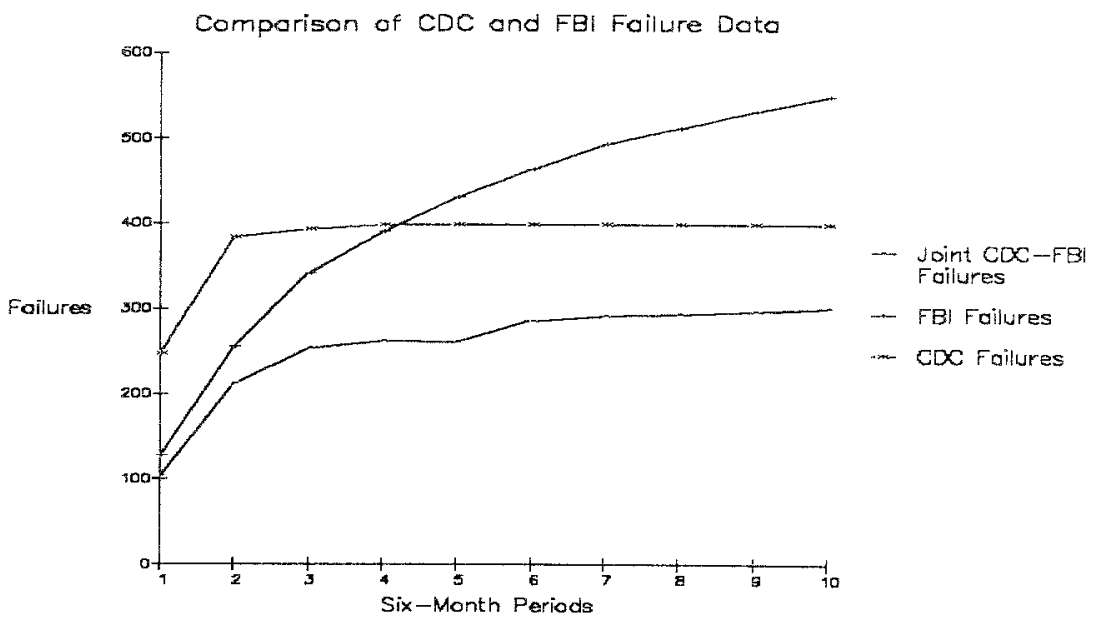

Fig. 1. Comparison of CDC and FBI failure data.

24 months. For example, during the first 6 months after release, there are 128 failures in the FBI-only data and 247 failures in the CDC-only data but only 104 failures jointly defined by both sources. And the gap widens after that. We cannot account fully for such discrepancies, but we do have some plausible explanations.

At least part of the problem stems from the different paths that reports take to the two agencies. The CDC data come directly from parole officers, who are required to document all officially designated parole violations. In contrast, the FBI data come from police departments and, typically, include only violations that led to an arrest or arrests, usually without mention of parole violations. ${ }^{5}$ Moreover, not all police departments send arrest reports to the FBI. Another complication is that CDC records do not explicitly distinguish parole violations that result in a return to prison from parole violations that do not result in a return to prison--violators may be given credit for time served in jail awaiting the parole revocation hearing. The best we could do in the CDC data was infer when reincarceration occurred. In contrast, the FBI data were coded so that a failure required clear evidence of time served. That is, a failure was recorded when there was a conviction and evidence that at least 3 months were spent confined. ${ }^{6}$ A similar determination could not be made from the CDC data.

\footnotetext{
${ }^{5}$ The one exception occurs when, under California law, the parole agent arrests the parolee in order to take him/ her into custody.

${ }^{6}$ In order to screen out apparently minor violations, we decided that some minimum threshold had to be exceeded before reincarceration was assumed. We felt that this was evidence, aside from the statutory charge, of a more serions infraction.
} 
The disparities between the two data sources are troubling, and we know of no fully satisfactory way to construct a composite outcome measure. However, since it is only in the FBI data that long-term trends can be pursued, the FBI data, of necessity, serve as the source of information on failures. In other words, failures that are reported only in the CDC data are ignored. Our reliance solely on the FBI data no doubt means that some unknown number of failures is not counted. Yet, such underreporting should not matter unless the underreporting is associated with the treatment after proper statistical controls are introduced. We discuss in the next section the issue of what constitutes proper statistical controls.

\subsection{The Regression-Discontinuity Design}

The strong legislative language requiring an impact assessment was not matched with a commitment to a randomized experiment. Yet since eligibility was fully determined by a single threshold of prison earnings, the legislation generated de facto a regression-discontinuity design (Campbell and Stanley, 1963; Cook and Campbell, 1979). Such a design was not planned by the legislation's sponsors; it simply happened, but the resulting data can be analyzed as if a planned regression-discontinuity design had been carried out. The regression-discontinuity approach is perhaps the strongest quasi-experimental design known, and it is to the properties of the design that we now turn.

Justification for the regression-discontinuity design can be found in Rubin's (1978) concept of "ignorability". Imagine, as in Fig. 2, that some response variable $R$ (e.g., a felony arrest) is a function of the presence or absence of some treatment $T$ (e.g., eligibility for unemployment benefits), a set of $X$ covariates (e.g., prior record, age, marital status, etc.), and a

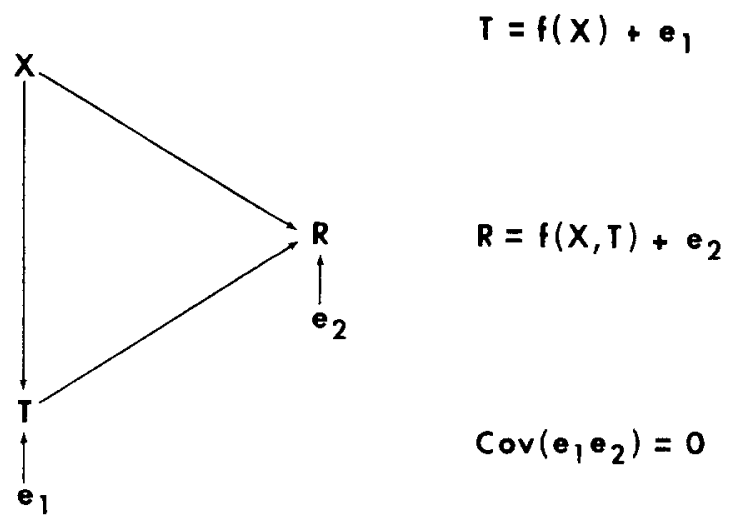

Fig. 2. Path diagram illustrating ignorability. 
disturbance process $e_{2}$ that meets the usual OLS assumptions. Also imagine that assignment to the treatment and control conditions depends on $X$ and some disturbance process $e_{1}$ meeting the usual OLS assumptions. Finally, assume that the two disturbance processes are unrelated and that $f(X, T)$ is a linear function.?

For the assignment process to be ignorable, all of the covariates included in $X$ must be known, measured, and used in any analysis of the treatment's impact on $R$. Thus, if the analysis is undertaken with multiple regression, the set of variables in $X$ would define the full set of required regressors.

Note that in Fig. 3, variables represented by $Z$, which affect the response but not the assignment of $T$, can be safely ignored. Since the $Z$ 's do not affect both $T$ and $R$, unbiased estimates of the impact of $T$ on $R$ can be obtained even if the $Z$ 's are not taken into account. (However, including the $Z$ variables in an analysis of any treatment effects will improve one's statistical power.)

For ex post facto designs, it is very difficult to demonstrate that all of the covariates in $X$ have been included. That is, when the researcher is simply presented with a set of observational data, the possibility of specification error clouds all substantive interpretations. And unfortunately, with the exception of the LIFE and TARP experiments, ex post facto designs dominate the literature on recidivism.

The best method to minimize the possibility of specification error is to employ random assignment to treatment and control conditions. Looking

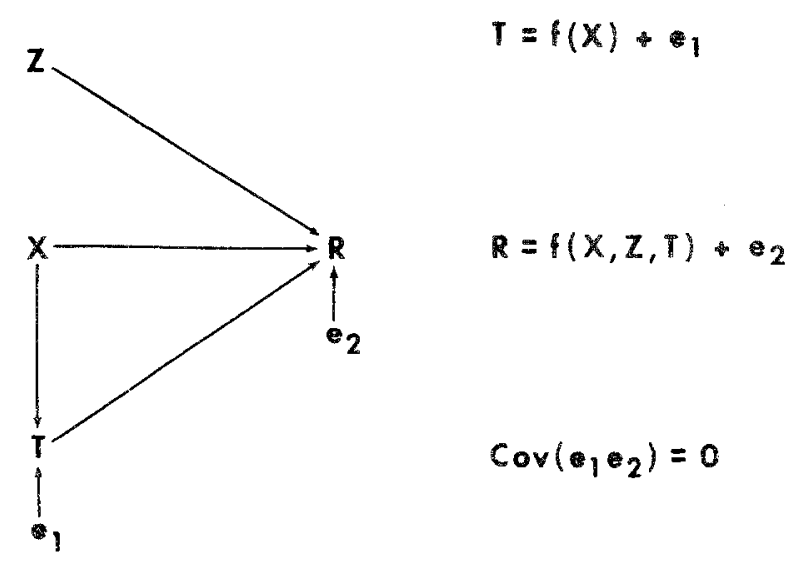

Fig. 3. Path diagram illustrating ignorability.

\footnotetext{
${ }^{7}$ The assumption of linearity is crucial. We discuss this assumption later.
} 
back at Fig. 2, the link between $X$ and $T$ is cut; the assignment mechanism is solely a function of some chance process represented by $e_{1}$. Consequently, the $X$ variables are effectively transformed into the $Z$ variables shown in Fig. 3. In this situation, omitting the $X$ 's can only reduce one's statistical power.

A weaker but still potent alternative is to use a deterministic assignment process. Looking at Fig. $4, A$ represents some assignment variable (or variables) interposed between $X$ and $T$. Under the provisions of SB224, prison earnings were such a variable. If a subject's value on $A$, or a scaled combination of $A$ 's, falls below (above) some threshold, the subject is given the control condition. If the subject's value falls on or above (below) the threshold, the subject is given the experimental condition. The impact of $X$ on $T$ is now funneled completely through $A$. Holding $A$ constant in an analysis of the impact of $T$ on $R$ will, in principle, yield unbiased estimates regardless of the presence or absence of $X$ (Rubin, 1977).

One drawback to this alternative is that the functional form of the relationship between $A$ and $R$ must be closely approximated. Cook and Campbell (1979, pp. 137-142) stress that failure to specify properly the functional form between $A$ and $R$ may well produce "pseudo-effects." As Rubin (1977) explains, the generic problem is that the regression of $R$ on $A$ must, for the experimentals, be extrapolated into the region of the controls, while for the controls, the regression of $R$ on $A$ must be extrapolated into the region of the experimentals. This is because there are no experimentals below (above) the threshold on $A$ and no controls above (below) the threshold on $A$. Thus, there are no data to test directly the appropriateness of the extrapolations. A second drawback is that the regression-discontuinity approach results in less statistical power than random assignment. The
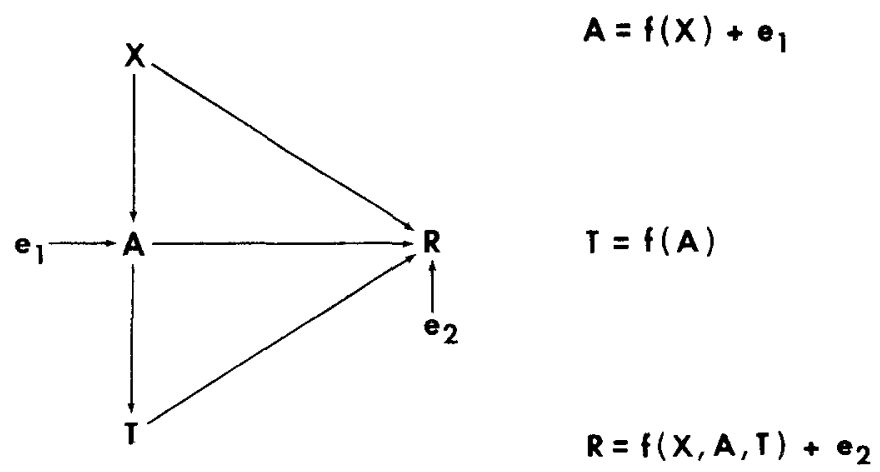

Fig. 4. Path diagram illustrating ignorability. 
inevitable correlation between the assignment variable and the treatment dummy variable will increase the variance of any estimates of the treatment effect. As a result, one typically needs larger samples and/or larger treatment effects than under random assignment.

To summarize (see also Berk and Rauma, 1983), the regression-discontinuity design, while weaker than a true experimental design, is far superior to an ex post facto design in which the assignment process is not well understood. For the analysis of unemployment compensation, our assignment variable $(A)$ is prison earnings. The covariates include such variables as age, sex, race, prior record, and drug history. These are a standard array of background and parole-related variables chosen for their impact on postprison adjustment. The response variable is the elapsed time between release and a return to prison for a new offense. In other words, we analyze our regression-discontinuity design within a failure-time statistical framework.

\subsection{The Time-to-Failure Model}

In our earlier work, we relied primarily on a binary outcome (fail or not) and a logistic regression model for the analysis of the regressiondiscontinuity data (Berk and Rauma, 1983). However, one can improve on statistical efficiency by using techniques that take as the dependent variable the elapsed time between exposure to the experimental or control condition and either a failure or the end of the follow-up period. Failure-time models have a long history in biostatistics and have been used in criminal justice research since the late 1970s (e.g., Maltz and McCleary, 1977).

We report failure-time results for the 5-year period after release from prison. For computational convenience, we employ follow-up data grouped into ten 6-month time intervals. This amounts to estimating a logistic regression (using a binary outcome) for each time period, with all coefficients except the intercepts constrained to be equal across time periods. Each logistic regression includes only those individuals still at risk (i.e., those who have not yet failed) during the time period in question.

The analytic cost of grouping into discrete time intervals is small. As the number of the time periods increases and as the duration of each time period decreases, the discrete model approaches the Cox proportional hazard regression formulation in continuous time (Lawless, 1982, pp. 372377). Our experience is that the approach occurs very quickly and that results in continuous time would not be substantively different. ${ }^{8}$

\footnotetext{
${ }^{8}$ Note that by using only those individuals still at risk, one is taking right-hand censoring formally into account in each of the logistic regressions.
} 


\section{FINDINGS}

Table I shows some selected descriptive statistics for our final sample. ${ }^{9}$ By and large, the statistics reveal just about what one would expect and what earlier experimental studies have shown. A majority of the sample is male $(97 \%)$, a minority is white $(45 \%)$, the mean IQ is well within the

Table I. Selected Descriptive Statistics $(N=1072)$

\begin{tabular}{|c|c|c|c|c|}
\hline Variable & Mean & SD & Minimum & Maximum \\
\hline Parole failure (dummy) & 0.53 & 0.50 & 0 & 1 \\
\hline Received benefits (dummy) & 0.79 & 0.41 & 0 & 1 \\
\hline Maximum weekly benefits $(\$)^{a}$ & 44.80 & 10.53 & 30.0 & 100.0 \\
\hline $\begin{array}{l}\text { Time between release and } \\
\text { application (weeks) }\end{array}$ & 1.86 & 2.63 & 0 & 8.7 \\
\hline Time between application and & & & & \\
\hline first benefits (weeks) ${ }^{a}$ & 5.08 & 2.04 & 4.3 & 21.7 \\
\hline Age at release (years) & 32.37 & 8.27 & 20 & 63 \\
\hline Male (dummy) & 0.97 & 0.16 & 0 & 1 \\
\hline White (dummy) & 0.45 & 0.50 & 0 & 1 \\
\hline Opiate addict (dummy) & 0.39 & 0.49 & 0 & 1 \\
\hline Has escape history (dummy) & 0.18 & 0.38 & 0 & 1 \\
\hline Has juvenile commitments (dummy) & 0.34 & 0.47 & 0 & 1 \\
\hline Number of prior prison terms (integers) & 0.58 & 0.97 & 0 & 4 \\
\hline Grade placement score (integers) & 7.55 & 2.91 & 0 & 12 \\
\hline IQ score (integers) & 92.87 & 11.27 & 68 & 140 \\
\hline Length of last prison term (months) & 30.75 & 24.64 & 3 & 244 \\
\hline Length of last camp term (months) ${ }^{h}$ & 1.66 & 3.95 & 0 & 27 \\
\hline Was released on work furlough (dummy) & 0.05 & 0.21 & 0 & 1 \\
\hline Released to Los Angeles county (dummy) & 0.29 & 0.45 & 0 & 1 \\
\hline Released to San Diego County (dummy) & 0.07 & 0.25 & 0 & 1 \\
\hline Released to San Francisco County (dummy) & 0.07 & 0.25 & 0 & 1 \\
\hline Released to Alemeda County (dummy) & 0.07 & 0.25 & 0 & 1 \\
\hline Parole Region 1 (dummy) & 0.22 & 0.41 & 0 & 1 \\
\hline Parole Region 2 (dummy) & 0.27 & 0.44 & 0 & 1 \\
\hline Parole Region 3 (dummy) & 0.24 & 0.43 & 0 & 1 \\
\hline Parole Region 4 (dummy) & 0.26 & 0.44 & 0 & 1 \\
\hline
\end{tabular}

${ }^{a}$ For ex-offenders who received benefits $(N=842)$.

${ }^{h}$ Most people had no camp time.

${ }^{9}$ The sample size differs from the earlier study, for several reasons. First, a number of individuals have died since their release from prison in the late 1970s. Their FBI files have been closed and the information is not readily accessible. Second, some individuals who were previously eliminated from consideration because their follow-up was less than 10 months have now been added. In each instance, the number of cases was small and not likely to affect the substantive outcome. 
average range (93), the mean educational grade placement score is well under 12 years of age (7.6), a substantial minority had experienced commitments as juveniles ( $34 \%$ ), and most were released from moderately long sentences ( 31 months). And these distributions of demographic characteristics in the sample are not very different from the distributions of the same characteristics in the population of all inmates released during the same period, 1977-1979 (see Berk and Rauma, 1983). It is also possible to learn a bit about the treatment from Table I. On the average, applicants filed for benefits about 2 weeks after release, and benefits arrived on the average about 5 weeks later. In the experimental group, the mean maximum payments for which individuals were eligible was $\$ 45.00 .^{10}$

Figure 5 shows a graph of the cumulative proportion of ex-prisoners reincarcerated, broken down by months after application and by membership in the experimental or control group, for both CDC and FBI sources of data. Three conclusions are easily drawn. First, when one compares simply the failure proportions for the experimentals and controls, without any partialing, it is clear that members of the control group are substantially more likely to fail, regardless of the data source. In the FBI data, the gap between the experimentals and the controls ranges from about 5 to about $12 \%$ and even the smallest disparities are statistically significant at the 0.05 level.

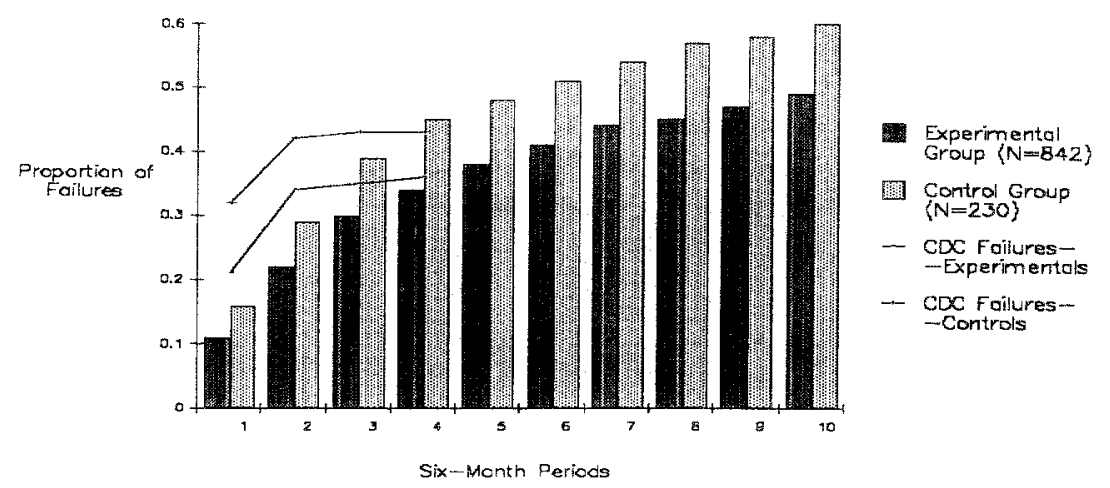

Fig. 5. Gross treatment effects by length of follow-up period.

${ }^{10}$ Our experimental and control groups were carefully screened so that individuals who had other sources of unemployment eligibility were excluded. Individuals who did not accumulate sufficient hours in prison to qualify for the benefits could combine these hours with employment after release in order to receive benefits. These "combined" compensation claims were excluded from the analysis, as were disability insurance claims. Together, these other types of claims accounted for only about $6 \%$ of all claims from the beginning of the program through January 1, 1981. For all practical purposes, therefore, benefits were delivered solely on the basis of prison earnings. 
Second, the CDC and FBI data, despite the anomalies described earlier, agree that there is a difference between experimental and control groups. One possible and important explanation is that the data source may be largely independent of the treatment assignment process and of individual failures. In other words, we are no more likely to find experimentals or controls failing in one data source or the other. This graphical evidence is not conclusive, but it is certainly more comforting than a result showing the predicted treatment effect in one data source and the opposite effect in the other.

Third, focusing exclusively on the FBI data, the arithmetic difference between the experimentals and the controls increases month by month up to about 24 months at risk. After 2 years, there is a roughly constant difference of about 0.10 between the two groups. In other words, differences in rates of recidivism occur within the first 2 years; afterward, the rates are fairly constant. Perhaps most importantly, the experimental and control groups do not converge. Thus, these gross treatment results appear to show that the unemployment compensation does not postpone criminality; rather, a difference is made early in the postprison experience that remains for at least the next few years.

As an introduction to the failure-time results, consider Table II. The cross-tabulation at the top of the table builds directly on Fig. 5; it shows the treatment effect at 6 months. The statistics to the right of the crosstabulation, particularly the odds ratio and the logarithm of the odds ratio, have direct analogues in the multivariate tables. The odds ratio is 0.65 , while the $\log$ of the odds ratio is -0.43 . Both imply that the odds of failure for the experimentals is about two-thirds the odds of failure for the controls.

The cross-tabulation at the bottom of Table II shows the treatment effect at 60 months. And to the right is a set of statistics parallel to those provided for the first cross-tabulation. One important result is that, while the treatment effect looks bigger at 60 months than at 6 months in simple difference terms, the odds ratios for the two time points are very similar. That is, once one takes the base failure rate into account in each period, the gross treatment effects are comparable; the odds of failure for the experimentals are about two-thirds the odds of failure for the controls.

Table III contains the maximum-likelihood estimates and significance tests for the logistic time-to-failure model. The 10 period constants allow for different intercepts for each logistic regression estimated. The initial conclusion to be drawn from this table is that, for people still at risk to fail (i.e., those who have not yet failed), the probability of failure by and large declines as the follow-up period increases. Perhaps the poor parole risks simply fail early, leaving behind a poor of better parole risks. Alternatively, the process of staying out of trouble itself produces benefits that, over time, 
Table II. A Tabular Representation of the Gross Treatment Effects

\begin{tabular}{|c|c|c|c|c|}
\hline \multicolumn{5}{|c|}{6 months at risk } \\
\hline & Failed & Not failed & & \multirow{4}{*}{$\begin{array}{l}\text { Failure odds (experimentals) }=0.12 \\
\text { Failure odds (controls) }=0.19 \\
\text { Odds ratio } \\
\quad \text { (experimentals } / \text { controls })=0.65 \\
\text { Natural log of odds ratio }=-0.43\end{array}$} \\
\hline Experimentals & $\begin{array}{l}0.11 \\
(91)\end{array}$ & $\begin{array}{c}0.89 \\
(751)\end{array}$ & $\begin{array}{c}0.79 \\
(842)\end{array}$ & \\
\hline \multirow[t]{2}{*}{ Controls } & $\begin{array}{l}0.16 \\
(37)\end{array}$ & $\begin{array}{c}0.84 \\
(193)\end{array}$ & $\begin{array}{c}0.21 \\
(230)\end{array}$ & \\
\hline & $\begin{array}{c}0.12 \\
(128)\end{array}$ & $\begin{array}{c}0.88 \\
(944)\end{array}$ & 1072 & \\
\hline \multicolumn{5}{|c|}{60 months at risk } \\
\hline & Failed & Not failed & & \multirow{4}{*}{$\begin{array}{l}\text { Failure odds (experimentals) }=0.96 \\
\text { Failure odds (controls) }=1.50 \\
\text { Odds ratio } \\
\quad \text { (experimentals } / \text { controls })=0.64 \\
\text { Natural log of odds ratio }=-0.45\end{array}$} \\
\hline Experimentals & $\begin{array}{c}0.49 \\
(410)\end{array}$ & $\begin{array}{c}0.51 \\
(432)\end{array}$ & $\begin{array}{c}0.79 \\
(842)\end{array}$ & \\
\hline \multirow[t]{2}{*}{ Controls } & $\begin{array}{c}0.60 \\
(138)\end{array}$ & $\begin{array}{l}0.40 \\
(92)\end{array}$ & $\begin{array}{c}0.21 \\
(230)\end{array}$ & \\
\hline & $\begin{array}{c}0.51 \\
(548)\end{array}$ & $\begin{array}{c}0.49 \\
(524)\end{array}$ & 1072 & \\
\hline
\end{tabular}

improve an ex-prisoner's chances. The former can be conceptualized as a type of individual heterogeneity, while the latter can be conceptualized as a type of state dependence (Hsiao, 1985, pp. 124-126).

Recall that the key to a credible analysis of regression-discontinuity data lies in properly modeling the relationship between the assignment variable (hours worked in prison) and the outcome variable (time to failure). We began with a single, linear variable of hours worked in prison. Then, as the literature suggests (e.g., Trochim, 1984), we experimented with polynomial functions of hours worked in prison, hoping to catch important nonlinearities. We also estimated separate logistic regressions for each of the 10 points in time (i.e., constraining none of the estimates across equations), trying polynomial functions of hours. Applying significance tests to these efforts, we arrived at the three variables for hours worked in prison shown in Table III: a linear function of hours worked for time periods 1 through 6 , another linear function of hours worked for periods 7 through 10 , and a quadratic function of hours worked for periods 1 through 6 . Nevertheless, it is apparent from their coefficients and $t$ values 
Table III. Maximum-Likelihood Estimates for the Time-to-Failure Model

\begin{tabular}{|c|c|c|c|}
\hline Variable & Coefficient & $t$ value & $P$ value \\
\hline Period 1 constant & -1.09 & -1.85 & 0.063 \\
\hline Period 2 constant & -1.06 & -1.78 & 0.074 \\
\hline Period 3 constant & -1.26 & -2.10 & 0.035 \\
\hline Period 4 constant & -1.65 & -2.81 & 0.005 \\
\hline Period 5 constant & -1.67 & -2.76 & 0.006 \\
\hline Period 6 constant & -1.89 & -3.09 & 0.002 \\
\hline Period 7 constant & -2.05 & -3.29 & 0.001 \\
\hline Period 8 constant & -2.49 & -3.88 & $0.000^{a}$ \\
\hline Period 9 constant & -2.07 & -3.33 & $0.000^{a}$ \\
\hline Period 10 constant & -2.51 & -3.33 & $0.000^{a}$ \\
\hline Hours worked in prison, periods $1-6$ & 0.17 & 0.47 & 0.565 \\
\hline Hours worked in prison, periods $7-10$ & -0.01 & -0.30 & 0.976 \\
\hline Hours worked in prison squared, periods $1-6$ & -0.12 & -1.02 & 0.309 \\
\hline Eligible for treatment (dummy) & -0.25 & -1.32 & $0.095^{b}$ \\
\hline Addict (dummy) & 0.50 & 5.40 & $0.000^{a}$ \\
\hline Age (years) & -0.04 & -4.72 & $0.000^{a}$ \\
\hline $\begin{array}{l}\text { Months served in CDC camp during } \\
\text { prior commitment }\end{array}$ & -0.02 & -1.20 & 0.228 \\
\hline History of escapes (dummy) & 0.49 & 4.28 & $0.000^{a}$ \\
\hline Achievement test score (grade equivalent) & 0.01 & 0.52 & 0.599 \\
\hline IQ score & $-0.00^{\alpha}$ & -0.57 & 0.564 \\
\hline History of juvenile offenses (dummy) & 0.27 & 2.71 & 0.007 \\
\hline Male (dummy) & 0.46 & 1.42 & 0.153 \\
\hline White (dummy) & -0.20 & -1.93 & 0.054 \\
\hline Number of prior prison terms & 0.09 & 1.44 & 0.150 \\
\hline Released on work furlough (dummy) & -0.18 & -0.75 & 0.452 \\
\hline Paroled to Oakland (dummy) & 0.32 & 1.63 & 0.102 \\
\hline Paroled to Los Angeles (dummy) & -0.09 & -0.58 & 0.558 \\
\hline Paroled to San Diego (dummy) & -0.08 & -0.35 & 0.714 \\
\hline Paroled to San Francisco (dummy) & 0.03 & 0.17 & 0.868 \\
\hline Paroled to Region 2 (dummy) & 0.13 & 0.92 & 0.359 \\
\hline Paroled to Region 3 (dummy) & -0.08 & -0.39 & 0.694 \\
\hline Paroled to Region 4 (dummy) & 0.20 & 1.26 & 0.207 \\
\hline
\end{tabular}

${ }^{a}$ Decimal value is smaller than the number of decimal digits displayed.

${ }^{h}$ One-tailed test.

that the assignment variable is not strongly related to the outcome. This has implications that we discuss later.

We have included in the model a number of covariates beyond functions of hours worked in prison. If we were estimating a linear model, the sole purpose of these covariates would be to improve statistical power. Insofar as the error sum of squares is reduced, smaller standard errors result. However, for nonlinear models, the covariates play an additional and 
important role. In brief, even with a randomized experiment, heterogeneity among the assigned units in the outcome will, for a wide variety of nonlinear models, lead to a particular type of biased treatment effect estimate (Gail et al., 1984). For linear models, such as linear regression or analysis of variance (properly implemented), randomization will suffice to produce unbiased estimates of treatment effects, which as a consequence of random assignment and a linear functional form, are not dependent on the distribution of covariates in the population (from which the sample data are, in principle, drawn). However, for many nonlinear functional forms, such as the logistic, randomization will not yield the same result. The treatment estimate, for both linear and nonlinear models, compares the response within some population of a randomly selected unit exposed to the treatment with that of another randomly selected unit that is not exposed to the treatment. In contrast, the desired estimate of the treatment effect, for each given unit, is a comparison of that unit's response to the control condition to that same unit's response to the experimental condition. The problem with nonlinear models is analogous to the functional form problem of the regression-discontinuity analysis. In the case of the linear model, the treatment effect can be readily extrapolated to the unobserved responses of each sampled unit-the unobserved response of the treatment group to the control condition can be estimated by the observed response of the control group, and similarly, the unobserved response of the control group to the treatment condition can be estimated by the observed response of the treatment group. Nonlinear models are generally problematic on this issue. Whereas nonlinear models are necessarily population specific, linear models are not (Gail et al., 1984, p. 432). Consequently, in nonlinear models (with the exception of certain exponential functional forms), one obtains treatment estimates that are independent of the particular distribution of the covariates in the population only if all sources of heterogeneity are partialed out via covariates. Put differently, nonlinear models require proper model specification even when treatment assignment has been random.

Our regression-discontinuity design is meant to approximate closely the level of internal validity one may obtain with random assignment. However, even if we have managed to produce that close approximation, we remain vulnerable to the biasing effects of individual heterogeneity. Hence, the covariates in Table III are intended to account for important sources of individual heterogeneity. Note that a number of large and statistically significant coefficients are reported, all of which have sensible signs. For example, ex-prisoners who have been addicts, who are younger, who have a history of escape attempts, and who have a history of juvenile offenses are at much greater risk for reincarceration. Nevertheless, important heterogeneity may well remain, a point to which we return. 
In Table III, the point estimate for the impact of unemployment compensation eligibility is -0.25 . This translates into an odds ratio of 0.78 ; the odds of failing for the experimentals is 0.78 the odds of failing for the controls. In other words, the estimated treatment effect, partialing out functions of hours worked in prison and a number of other covariates, is a bit smaller than the gross treatment effects reported in Table II and Fig. 5. Using a null hypothesis of no effect and a one-tailed test, the treatment effect is statistically significant at the 0.10 level but not the 0.05 level. That is, if the treatment effect were really zero, a negative coefficient as large as the one obtained could have occurred about 1 time in 10 by chance alone.

There are a number of possible analytical responses to the estimated treatment effect. One option is to adopt (in advance) the 0.10 level of statistical significance and then reject the null hypothesis that the program did not work. If one has strong prior beliefs that the program reduced reincarceration rates and/or has a loss function in which false negatives are especially troubling, this is a reasonable response.

A second option is to adopt (again in advance) the more conventional 0.05 level of statistical significance and then fail to reject the null hypothesis of no effect. If one has few a priori preconceptions about the program's effects, or strong prior beliefs that the program is ineffective (or harmful), and/or a loss function in which false positives are especially troubling, this is a reasonable response.

Yet a third option is to adopt the 0.05 level of statistical significance but use a treatment effect as the null hypothesis that would allow the program financially to break even (rather than a null hypothesis of zero). We have estimated that a reduction in reincarceration rates of $5 \%$ overall would make the program cost effective. ${ }^{11}$ At the mean failure rate for both

${ }^{11}$ The total bill for SB224 cost California taxpayers about $\$ 15$ million. While this is hardly cheap, even small reductions in reincarceration attributable to the program would make the program cost effective. At the time the legislation was passed, a year in prison cost the State of California about $\$ 15,000$. Thus, the program would break even during its 5 -year lifetime if 1000 prison-years were prevented. There are a number of different and plausible patterns that might achieve such reductions. For example, assuming a modal term of 2 years (see Table I), only 500 new imprisonments would have to be averted in under 5 years. With well over 20,000 prisoners released yearly, and postulating a baseline reincarceration rate within 12 months of about $30 \%$ (see our descriptive data), 6000 individuals would ordinarily be returned to prison. If, as a result of unemployment insurance, 500 of these individuals (about $8 \%$ ) managed a successful reintroduction into society, the program would pay for itself in the first year alone. Given 5-year reincarceration rates of over $50 \%$ and 5 years to accumulate savings, it is clear that reductions of about $1 \%$ a year in reincarceration rates would easily pay for the program. And this ignores all of the other costs associated with crimes that would be eliminated (e.g., costs to victims). Clearly, SB224 could be a dramatic financial success with even small effects on recidivism rates. 
groups; the logistic coefficient of -0.25 translates into a difference between the experimentals and the controls of about $5 \%$. That is, the proportion of the experimentals who fail is about $5 \%$ less than the proportion of the controls who fail. Using the $5 \%$ figure as the basis of the null hypothesis (translated in a logistic regression coefficient), the null hypothesis cannot be rejected. One would, therefore, tentatively accept the null hypothesis that the program worked at a cost-effective level.

A fourth option would be to examine the data more closely to see if there are treatment effects obscured by a single, overall estimate of effect. To begin, we did not find important interaction effects for different kinds of offenders, although there was as suggestion that the program worked better for individuals who would have been better risks. For example, we did not find interaction effects by race. However, first-time offenders seemed to benefit more from eligibility (but not by greater than chance amounts) than offenders with a prior conviction record.

Far moie promising are the implications of fully separate logistic regressions run for each of the time periods. The treatment effect coefficient was $-0.29(t=-0.68)$ at 6 months grew to $-0.45(t=-1.49)$ at 24 months and then declined to $-0.22(t=-0.50)$ at 60 months. In other words, the effect was in the predicted direction in each time period but peaked at about 2 years after release.

If one takes this temporal pattern seriously, it suggests that any beneficial impact of eligibility is attenuated early when the high-risk cases are likely to fail and late when most of the individuals who remain in the pool are low risk. In other words, the treatment effect may be weak early because many potential recidivists are indeed very likely to get into trouble in spite of eligibility. Similarly, the treatment effect may be weak late because the survivors are very unlikely to get into trouble, even if eligibility were not available. In contrast, the treatment effect is greatest when the total pool at risk to reincarceration no longer has many sure losers but still is not constituted almost exclusively of sure winners.

The temporal pattern of treatment also has implications for why the overall impact of eligibility is smaller in this analysis compared to the analysis published earlier (Berk and Rauma, 1983; Rauma and Berk, 1982). In brief, if the treatment's impact declines dramatically after about 24 months, the average effect aggregated over the 60-month follow-up period will, in all probability, be attenuated compared to the average effect aggregated over the 10-month follow-up period.

A final response is to take seriously the concept of ignorability. Recall that for the assignment of a treatment to be ignorable, all covariates associated with both the treatment and the outcome must be included in the analysis. This clearly means that one need not include any covariates that 
are not related to both the treatment and the outcome. In our case, despite a variety of efforts to find statistically significant and large effects for various functions of hours worked in prison, we were unable to do so. Moreover, we paid a high price for including functions of hours; such functions were inevitably and highly associated with the treatment dummy variable. As a consequence, it is reasonable to drop hours worked in prison from the multivariate analysis. Any estimated treatment effect will be essentially unaltered because hours worked in prison is effectively unrelated to reincarceration. However, due to the reduction in collinearity, the associated standard error will decline, and consequently, the $t$ value will increase. In Table III, for example, the estimate of the treatment effect and the estimate of the impact of hours in the earlier time periods have a correlation of -0.70 . Similarly, the estimate of the treatment effect and the estimate of the impact of hours squared in the earlier time period have a correlation of -0.47 .

As anticipated, dropping hours worked in prison from the analysis had a very small impact on the estimated treatment effect but dramatically altered its associated $t$ value. The treatment effect increased slightly, from -0.25 to -0.30 , while for the null hypothesis of no effect the $t$ value increased substantially (in absolute value), from -1.31 to $-2.66(P<0.005)$. Clearly, our estimated treatment effect is now statistically significant by any conventional standard. A combination of a small change in the estimated treatment effect and a large change in the standard error apparently confirms our suspicion that hours worked in prison was not an important covariate. ${ }^{12}$

\section{CONCLUSION}

Together, the graphical display in Fig. 5 and our time-to-failure results in Table III are evidence for a reduction in recidivism due to unemployment compensation eligibility. Unfortunately, traditional criminological theory provides little clue as to how this reduction might be achieved. This is hardly surprising, since the vast majority of criminological thought has been devoted to issues concerning the initial differences between criminals and noncriminals. Until recently, continuing criminal behavior had not been addressed systematically and theoretically.

\footnotetext{
${ }^{12}$ We could have employed the same strategy for each of the other covariates in Table III that did not have statistically significant effects on reincarceration. However, the largest correlation between the estimated treatment effect and estimates of the impact of any of the other covariates was -0.18 . The typical correlation was about 0.10 in absolute value. Clearly, there was little to be gained in pruning the model further.
} 
Economic theory, such as we posited earlier, makes these results relatively easy to understand. In terms of opportunity costs, the unemployment compensation program made the cost of going back to prison higher than it ordinarily would have been. And although our analysis has used eligibility as the assignment variable for treatment and control groups, we do know that everyone in our treatment group received at least one weekly payment. What is most interesting, compared to the earlier TARP study, is that unemployment compensation's inherent work disincentives did not overwhelm the crime-reducing effect of the compensation.

In general, existing economic models do not predict whether individuals with additional nonlabor income (e.g., unemployment compensation) will choose to decrease their participation in legal income-generating activities, to decrease their participation in illegal income-generating activities, or some combination of the two. Rather, this is typically left to empirical estimation. TARP provides one set of estimates, in which some combination of the two takes place, with the net result being no apparent treatment effect. The earlier analysis of the California program showed that the opportunity costs operated even more strongly, the net result being an overall negative, albeit weak, treatment effect.

That the treatment effect seems to last for at least 5 years is support for the hypothesized treatment effect. Even if those receiving payments chose to remain out of work during their eligibility period, they may have put that time to good use. The TARP results showed that individuals in the treatment groups used their time to seek better jobs. Thinking back to the sporadic patterns of employment that a majority of ex-offenders experiences, the transfer payments in TARP and in the SB224 may have been enough to break this cycle for many of the former inmates. As a result, given increased opportunity costs associated with employment (and perhaps increasing opportunity costs as individuals stay longer on the job), differences between treatment and control groups, once established, are likely to remain for some time.

The policy implications of our findings are intriguing, although perhaps not politically palatable. Modest amounts of unemployment compensation do not lead to a net increase in criminality among released felons. The evidence from four states and three studies is that there is probably a net reduction in criminality. The theoretical implications are also enlightening. Economic models of crime are useful tools for understanding the role of economic factors in individual criminality. More research needs to be done, obviously, to understand better the time allocation process. For other social scientists, more theoretical work is also needed, to define better the reciprocal, temporal relationship between employment and crime. 


\section{ACKNOWLEDGMENTS}

We are indebted to Robert Dickover of the California Department of Corrections for his help in the data collection effort. This research was supported by Grant 83-IJ-CX-K047 from the National Institute of Justice.

\section{REFERENCES}

Becker, G. A. (1968). Crime and punishment: An economic approach, J. Polit. Econ. 76: 169-217.

Berk, R. A., and Rauma, D. (1983). Capitalizing on nonrandom assignment to treatments: A regression-discontinuity evaluation of a crime-control program, J. Am. Stat. Assoc. 78: 21-27,

Berk, R. A., Lenihan, K. J., and Rossi, P. H. (1980). Crime and poverty: Some experimental evidence from ex-offenders, Am. Sociol. Rev. 45: 766-786.

Block, M. K., and Heineke, J. M. (1975). A labor-theoretic analysis of criminal justice, Am. Econ. Rev. 65: 314-325.

Board of Prison Directors, California State Prison (1858). Annual Report, Superintendent of State Printing, Sacramento.

Board of Prison Directors, California State Prison (1905). Biennial Report for 1902-1904, Superintendent of State Printing, Sacramento.

Campbell, D. T., and Stanley, J. C. (1963). Experimental and Quasi-Experimental Designs for Research, Rand McNally, Chicago.

Cook, T. D., and Campbell, D. T. (1979). Quasi-Experimentation: Design and Analysis Issues for Field Settings, Rand McNally, Chicago.

Ehrlich, I. (1973). Participation in illegal activities: A theoretical and emprical investigation, J. Polit. Econ. 81: 521-565.

Freeman, R. B. (1983). Crime and unemployment. In Wilson, J. Q. (ed.), Crime and Social Policy, ICS Press, San Francisco, pp. 89-106.

Gail, M. H., Wieand, S., and Piantadosi, S. (1984). Biased estimates of treatment effect in randomized experiments with nonlinear regressions and omitted covariates, Biometrica $71: 431-444$.

Glaser, D. (1964). The Effectiveness of a Prison and Parole System, Bobbs-Merrill, Indianapolis.

Heineke, J. M. (1978). Substitution among crimes and the question of deterrence: An indirect utility function approach to the study of crime. In Heineke, J. M. (ed.), Economic Models of Criminal Behavior, North-Holland, Amsterdam.

Hsiao, C. (1985). Benefits and limitations of panel data, Economet. Rev. 4: 121-174.

Lawless, J. F. (1982). Statistical Models and Methods for Lifetime Data, John Wiley, New York.

Lenihan, K. J. (1978). Unlocking the Second Gate: The Role of Financial Assistance in Reducing Recidivism Among Ex-Prisoners, R\&D Monograph 45, U.S. Department of Labor, Employment and Training Administration, Washington, D.C.

Liker, J. K. (1982). Wage and status effects of employment on affective well-being among ex-felons, Am. Social Rev. 47: 264-283.

Maltz, M. D. (1984). Recidivism, Academic Press, Orlando.

Maltz, M. D., and McCleary, R. (1977). The mathematics of behavioral change, Eval. Q. 1; 421-438.

Nock, S. S., and Rossi, P. H. (1978). Ascription versus achievement in the attribution of social status, Am. J. Sociol. 84: 541-564.

Pownall, G. A. (1969). Employment problems of released offenders, Report to the manpower administration, United States Department of Labor, Washington, D.C. 
Rauma, D., and Berk, R. A. (1982). Crime and poverty in California: some quasi-experimental evidence, Soc. Sci. Res. 11: 318-352.

Rossi, P. H., Berk, R. A., and Lenihan, K. J. (1980). Money, Work, and Crime: Experimental Evidence, Academic Press, New York.

Rossi, P. H., Berk, R. A., and Lenihan, K. J. (1982). Saying it wrong with figures: A comment on Zeisel, Am. J. Sociol. 88: 390-393.

Rubin, D. B. (1977). Assignment to treatment group on the basis of a covariate, J. Educ. Stat. 2: $1-26$.

Rubin, D. B. (1978). Bayesian inference for casual effects: The role of randomization, Ann. Stat. 6: 34-58.

Schmidt, P., and Witte, A. D. (1984). An Economic Analysis of Crime and Justice, Academic Press, New York.

Thornberry, T. P., and Christenson, R. L. (1984). Unemployment and criminal involvement: An investigation of reciprocal causal structure, Am. Sociol. Rev. 49: 398-411.

Trochim, W. M. K. (1984). Research Design for Program Evaluation, Sage, Beverly Hills, Calif.

Witte, A. D. (1975). Work Release in North Carolina: An Evaluation of its Post Release Effects, Institute for Research in Social Science, Chapel Hill, N.C.

Witter, A. D. (1976). Earnings and jobs of ex-offenders: A case study, Month. Labor Rev. 99: 31-39.

Wolfgang, M. E., Figlio, R. M., and Sellin, T. (1972). Delinquency in a Birth Cohort, University of Chicago Press, Chicago.

Zeisel, H. (1982). Disagreement over the evaluation of an experiment, Am. J. Sociol. 88: 378-389. 